\title{
The Effect of Immune Max in the Liver, Kidney and Spleen Histological Structure in Male Albino Mice
}

\author{
Mohammed Abed Jawad', Abed ] Kadhim², Saif Yaseen Hasan \\ ${ }^{1,2} \mathrm{Al}-\mathrm{Nisour}$ University College, Iraq. \\ ${ }^{3}$ National University for Science and Technology, Iraq. \\ DOI: https://doi.org/10.24321/0019.5138.202156
}

\section{I $\quad \mathbf{N} \quad \mathbf{F} \quad \mathbf{O}$}

\section{Corresponding Author:}

Mohammed Abed Jawad, Al-Nisour University

College, Iraq.

E-mail Id:

mohammed.a.medical.lab@nuc.edu.iq

Orcid Id:

https://orcid.org/0000-0002-0219-086X

How to cite this article:

Jawad MA, Kadhim AJ, Hasan SY. The Effect of Immune Max in the Liver, Kidney and Spleen Histological Structure in Male Albino Mice. J Commun Dis. 2021;53(3):186-189.

Date of Submission: 2021-08-04

Date of Acceptance: 2021-08-27

\section{$\begin{array}{llllllll}\mathbf{A} & \mathbf{B} & \mathbf{S} & \mathbf{T} & \mathbf{R} & \mathbf{A} & \mathbf{C} & \mathbf{T}\end{array}$}

Background: This study aimed to identify the effect of using the Immune Max dietary supplement on the histological composition of some organs in male albino mice.

Methods: The study was conducted on the Swiss albino male mice which were divided into two groups: treated group with $0.162 \mathrm{mg} / \mathrm{kg} /$ day of Immune Max and second group as a control.

Results: Histological examination was conducted for liver, kidney and spleen. The results showed some histological changes in these organs like loses of tissues, congestion, leukocytes infiltration and dead cells.

Conclusion: The purpose of a conclusion that the use of the Immune Max nutritional supplement can cause damage to the tissues of a number of organs and this is likely to be due to the dose concentration and the duration of the treatment.

Keywords: Immune, Tissues, Health

\section{Introduction}

There are more than 600 drugs that cause damage to the various organs, including the liver and kidneys, which can be repaired in the event of stopping the use of these drugs, but the situation can become worse if the use of such drugs continues, ${ }^{1}$ and some drugs cause damage to a specific organ more From other drugs, as some people are sensitive to the drug that causes damage compared to other people who take the same drug and the same dose. ${ }^{2}$ Health problems increased worldwide as a result of increased exposure to a number of modern drugs and medicines that are consumed by prescription or other such as complementary and nutritional supplements, and as a result of the influence of the liver with different drugs that led to the emergence of various pathological and clinical patterns that include Steatohpatitis, Chronic hepatitis and Cirrhosis. ${ }^{3}$ Kidney effects are glomerular atrophy, Bowman's purification, and renal papillary necrosis. ${ }^{4}$ In the spleen, drugs can cause the expansion of the blood vessels. Hemorrhagic within the spleen tissue as well as vascular congestion. ${ }^{5}$

Dietary supplements and some herbs cause many health problems if they are dealt with wrongly or in a random manner, as their damages reach important parts of the body such as the liver, kidneys and spleen. Some studies have indicated that there are 17 types of supplements that cause damage to different body organs. ${ }^{6}$ Supplements is Immune Max, which is one of the supplements that work to raise 
the immune response and the formation of erythrocytes and ovarian blood cells because it contains yucca, lactin, and beta-cancer, and reduces the negative effect of free radicals because it contains selenium and vitamin $E$, also helps in wound healing and treatment of arthritis, and also helps the body in getting rid of Mycotoxins. Immune Max contains many groups of vitamins, including B 1,2,6,12, A, $C$, D. It also contains minerals such as selenium, zinc and iron, which helps in strengthening memory and increasing concentration. ${ }^{7}$

There are many commonly used drugs that give side effects in spite of their use as a therapeutic or preventive drug, there is no non-toxic chemical, but the appropriate dose for a particular object according to its type, age and weight determines the toxicity of the substance and its effect on the organism. ${ }^{6}$

This study aimed to identify the effect of using the Immune Max dietary supplement on the histological composition of some organs in male albino mice.

\section{Materials and Methods}

The study was conducted on the Swiss albino male mice
(20 mice). They ranged in age from 4-5 weeks and weighed 25-30 g Experimental animals were divided into two groups and at the rate of mice for each group10, first group treated with $0.2 \mathrm{~mL}$ of Max Immune at concentration $0.162 \mathrm{mg} /$ $\mathrm{kg} /$ day for 14 days, while the second group treated with N.S. as a control. The mice were killing by spinal dislocation then explained and collected the organs liver, kidney and spleen for testing.

Histological preparation was used in tissue preparations according to Bancroft JD et al.8 to examine the histopathological changes.

\section{Results}

The results of the current study showed the effect of liver tissue in rats treated with dietary supplement $(0.162 \mathrm{mg} /$ $\mathrm{kg} /$ day) and for 14 days some pathological changes occurred compared with the liver tissue in control animals (Figure $1 \mathrm{~A}$ ), as it was possible to notice severe blood congestion in the central vein and infiltration of leukocytes within Liver tissue (Figure 1B), a loses within the liver tissue was observed in the central lobular region, an increase in the number of vacuolated cells, as well as the binuclear hepatocytes and death of some cells within the liver tissue (Figure $1 \mathrm{C}$ ).

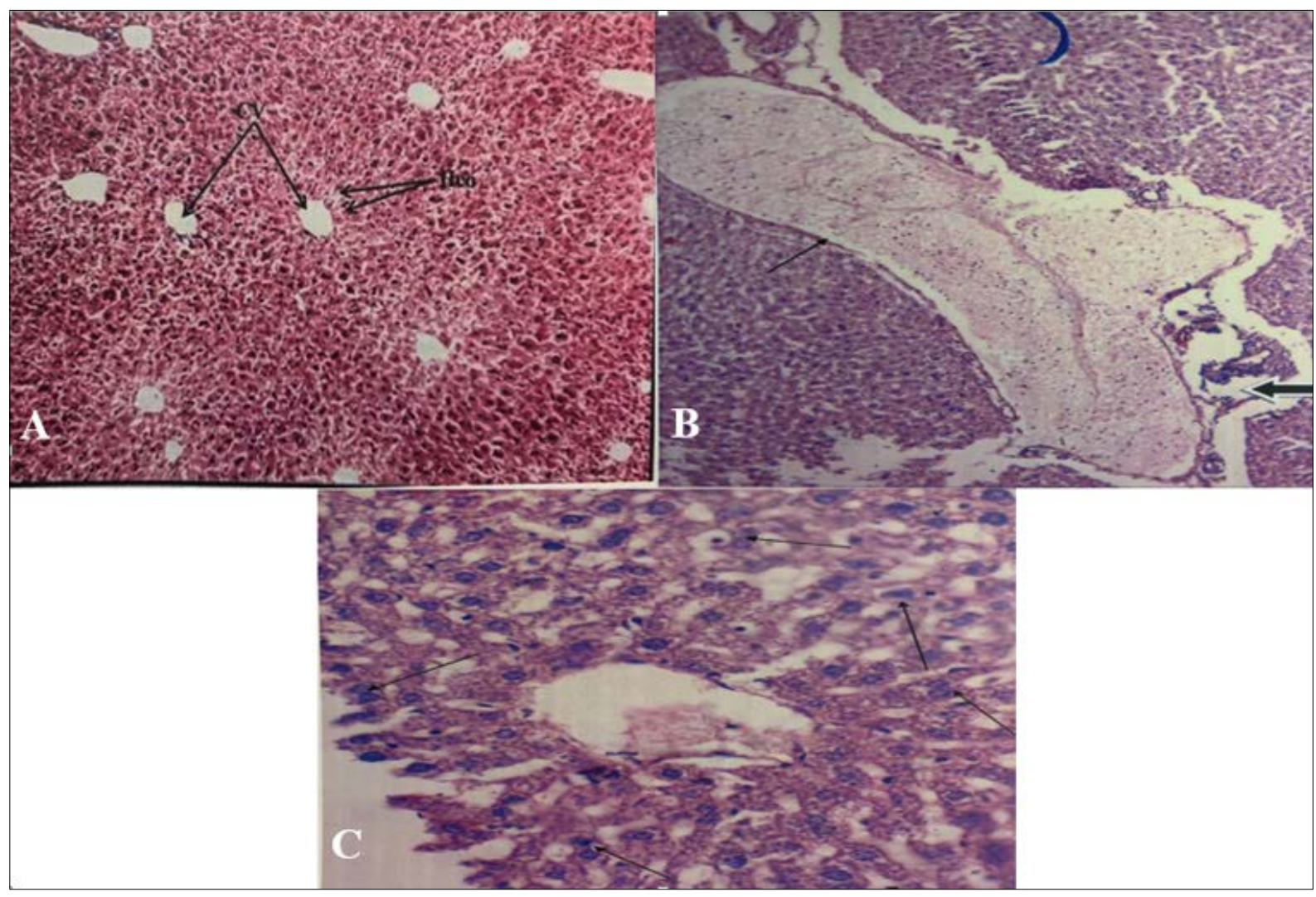

A - Control Group (10x), B - Treated Group with Immune Max Showed Blood Vessels Congestion and Leukocytes Infiltration (10x), C - Treated Group Showed Vacuolated Cells, Binuclear Hepatocytes and Dead Cells (H \&E) (40x)

Figure I.Cross Section in Liver of the Mice 
As for the most important changes that were observed in the kidney tissue in treated mice, the glomerular atrophy and the expansion of intercapsular space within the Bowman capsule and the shrinkage of cells lining the urinary tubules (Figure $2 \mathrm{~A}$ ) in both the cortical and pulp region of the kidneys, as well as the separation of some cells lining the urinary tubules from the basement membrane (Figure 2B) compared to the kidney tissue In control animals.

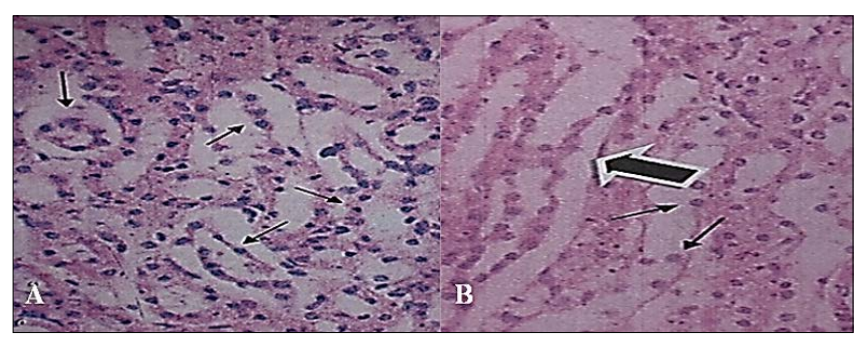

A - Showed the Atrophy of Glomerulus in the Cortex and B the Shrinkage of Cells (H\&E) 40x

\section{Figure 2.Longitudinal Section in the Kidney of} Treated Mice

In the spleen, hemorrhage was observed within the spleen tissue in animals treated with dietary supplement resulting from vascular damage and looses within the lymphatic tissue (Figure $3 A$ ), especially in the white pulp and red pulp, as was the presence of a proliferation of giant cells within the red pulp region of the spleen and an increase the dead cells (Figure 3B).

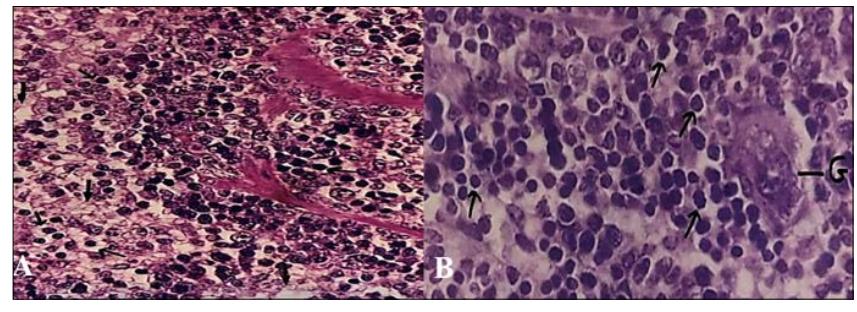

A - Looses in Tissue, B - Presence of Giant Cells in the Red Pulp (H\&E) 40x

Figure 3.Section in the Spleen of Treated Mice

\section{Discussion}

The result of the histological examination of the tissue of the liver of mice treated with the food supplement Immune Max showed a loss of the normal structural composition and the appearance of loses in the liver tissue. It is caused by the effect of the dose used from the dietary supplement $(0.162$ $\mathrm{mg} / \mathrm{kg}$ ) for 14 days, it probably stimulated the mechanisms of cell death in the liver tissue, as there are a number of mechanisms that stimulate damage in cells, including the liver cells, including an increase in the concentration of $\mathrm{Ca}$ ++ ions inside the cell, this stimulates a group of enzymes, including enzymes digestion of cellular membrane proteins and cellular structure Proteases, and endonucleases enzymes responsible for cutting DNA strips, and that the plasma membrane of hepatocytes is damaged by necrosis which altering the permeability of the plasma membrane and releasing the cell contents to the outer circumference. ${ }^{9}$

Some studies ${ }^{10}$ indicated that some drugs can cause histopathological changes in the liver represented by congestion in the central vein, as congestion in the central veins is caused by the death of liver cells and their necrosis, which stimulates the occurrence of inflammatory reactions against them for the purpose of removing them from the liver tissue that It results in a widening of the blood vessels, congestion in the blood, altering their permeability, and then the transfer of single-core white blood cells and neutrophils from the bloodstream to the adjacent tissues for the purpose of cleaning the liver tissue from the dead cells, ${ }^{11}$ and this is observed in this study of leakage Moderate average white blood cells in the central lobular region and vascular congestion within the liver tissue.

There are some drugs that are responsible for kidney disease, such as side effects of glomeruli and renal tubules. The results of the current study showed the glomerular atrophy and the widening of the intercapsular space within the Bowman's purse and the shrinkage of cells lining the urinary tubules in both the cortex and the pulp of the kidney, as some separation was observed. Cells lining the urinary tubules from the basement membrane that such damage may also be caused by a dose of a nutritional supplement or a daily dose of 14 days, which is one of the defensive means of adapting to the toxicity of the dose used to keep the cells as alive as possible and hinder the effect of the dose to the blood stream. ${ }^{12}$

As for the spleen tissue, the disintegration of the lymph tissue was observed, especially in the area of the white pulp and the red pulp, as was the presence of a number of giant cells within the area of the red pulp of the spleen and an increase in the numbers of dead cells. The use of the immune max as a stimulant to the immune system and immune cells, which stimulates the attraction of single cells from bone marrow into the bloodstream and then migrates to neighboring tissues after differentiation into macrophages and the formation of giant cells, ${ }^{2}$ this is in agreement with the result of the current study and the proliferation of giant cells within the tissue of the spleen to remove damaged and dead cells due to the dose used, as the damage may be caused by the activity of macrophages and giant cells by themselves through their production of lysozymes that would cause damage to the tissue. ${ }^{13}$

\section{Conclusion}

The use of the Immune Max nutritional supplement can cause damage to the tissues of a number of organs in the group of mice used in this study, and this is likely to be due to the dose concentration and the duration of the dose. 


\section{Conflict of Interest: None}

\section{References}

1. Lee RG. Diagnostic liver pathology. Mosby, USA. 1989, p.517.

2. Pauls LL, Senior JR. Drug-induced liver injury (DILI). Clinical Investigator Training Course, Office of Surveillance and Epidemiology, Center for Drug Evaluation and Research, Food and Drug administration. November, 2012, p.1-45.

3. Lucena MI, Cortes MG, Cueto R, Duran IL, Andrade RJ. Assessment of drug-induced liver injury in clinical practice. Fundam Clin Pharmacol. 2008 Apr;22(2):14158. [PubMed] [Google Scholar]

4. Sahu C, Ghosal J. Pathological manifestation of piroxicam (COX-inhibitor) induced Hepato-nephrotoxicity in mice. J. Herbal Med. Toxicol. 2007;1(2):23-8.

5. Anderson WAD. Pathology. 6th ed. The C.V. Mosby Company, USA. 1971. 1862 pages.

6. Souza RA, Miranda H, Ribeiro W. Effects of high-dose creatine supplementation on kidney and liver responses in sedentary and exercised rats. J Sports Sci Med. 2009 Dec 1;8(4):672-81. [PubMed] [Google Scholar]

7. Maggini S, Pierre A, Calder PC. Immune function and micronutrient requirements change over the life course. Nutrients. 2018 Oct 17;10(10):1531. [PubMed] [Google Scholar]

8. Bancroft JD, Cook HC, Turner DR. Manual of histological techniques and their diagnostic application. 2nd ed. Churchill Livingstone, London. 1994, p.457.

9. Gond NY, Khadabadi SS. Hepatoprotective activity of Ficuscarica leaf extract on rifampicin-induced hepatic damage in rats. Indian J Pharm Sci. 2008;70(3):364-6. [PubMed] [Google Scholar]

10. Ahmed DF. The effect of rifampicin and isoniazid on liver and lung tissue in rats. Irq J. Pharm. 2011;11(2):34-45. [Google Scholar]

11. Kumar AS, Samanta KC, Chipa RC. Hepatoprotective activity of alcoholic and aqueous extract of leaves of Anisochilus carnosus (Linn.) wall. Int. J. Pharm. Life Sci. 2010;1(2):99-104. [Google Scholar]

12. Kumar V, Abbas AK, Fausto N, Mitchell R. Robbins basic pathology. 8th ed. Saunders, Elsevier. 2007, p.632-634.

13. Paul WE. Fundamental immunology. 4th ed. LippincottRaven, Philadelphia. 1999. 